\title{
ABORDAGENS SOBRE A TRANSPARÊNCIA EM ESTUDOS DE ADMINISTRAÇÃO PÚBLICA NO BRASIL
}

\author{
REIS, Anderson de Oliveira ${ }^{1}$ \\ SEDIYAMA, Gislaine Aparecida Santana ${ }^{2}$ \\ CASTRO, Elizangela Lourdes de
}

RESUMO: Os debates sobre transparência tem ganhado notoriedade no meio acadêmico por revelar as necessidades de se ampliar as formas de responsabilização do governante e defender as formas de controle social. O objetivo deste ensaio é identificar e aprofundar as análises sobre transparência com base nas correntes teóricas de administração pública propostas por Andion (2012). Trata-se de evidenciar as mudanças e salientar a continuidade de abordagens teóricas sobre transparência pública. A hipótese central é a de que apesar de se observar mudanças nos paradigmas de administração pública, há continuidade teórica nas abordagens sobre transparência predominando na concepção funcionalista do termo. No intuito de confirmar a hipótese procedeu-se revisão do trabalho de Andion (2012) com vistas a destacar os principais pontos sobre cada corrente teórica de administração pública. Em seguida, examinou-se as abordagens sobre transparência pública no Brasil, destacando-se a corrente teórica dos estudos sobre a temática e os paradigmas que lhes dão suporte. A hipótese central foi aceita, revelando que há predominância da abordagem funcionalista nos estudos sobre transparência sendo esta associada principalmente ao conceito de eficiência.

Palavras-Chave: Transparência. Abordagens teóricas. Administração pública.

SUMMARY: Discussions on transparency has gained notoriety in academic circles for revealing the need to expand forms of accountability of the governor and defend forms of social control. The essay aims to identify and deepen the analysis of transparency based on current theories of government proposed by Andion (2012). It is to highlight the changes and emphasize the continuity of theoretical approaches to public transparency. The central hypothesis is that although we did see changes in public administration paradigms, there is continuity in theoretical approaches to transparency predominating in the functionalist conception of the term. In order to confirm the hypothesis proceeded to review the Andion work (2012) in directive to highlight the key points about each theoretical current of public administration. Then examined whether the approaches to public transparency in Brazil, highlighting the theoretical current studies on the subject and the paradigms that support them. The central hypothesis is accepted, revealing that there is a predominance of the functionalist approach in studies on transparency and this is mainly associated to the concept of efficiency.

Keywords: Transparency. Theoretical approaches. Public administration.

RESUMEN: Los debates sobre la transparencia han ganado notoriedad en los círculos académicos por revelar la necesidad de ampliar las formas de rendición de las cuentas del gobernador y defender formas del control social. El propósito de esta prueba es identificar y profundizar el análisis de la transparencia sobre la base de las teorías actuales de gobierno propuestos por Andion (2012). Es de destacar los cambios y hacer hincapié en la continuidad de los enfoques teóricos para la transparencia pública. La hipótesis central es que, aunque nos hicieron ver los cambios en los paradigmas de la administración pública, hay continuidad en los enfoques teóricos a la transparencia que predominan en la concepción funcionalista del término. Con el fin de confirmar la hipótesis se procedió a revisar el trabajo Andion (2012) con el fin de destacar los puntos clave acerca de cada corriente teórica de la administración pública. Luego examinó si los enfoques de la transparencia pública en Brasil, destacando los estudios actuales teóricos sobre el tema y los paradigmas que los apoyan. La hipótesis central fue aceptada, revelando que hay un predominio del enfoque funcionalista en los estudios sobre la transparencia y esto se asocia principalmente con el concepto de eficiencia.

Palabras Clave: Transparencia. Enfoques teóricos. Administración pública.

\footnotetext{
${ }^{1}$ Universidade Federal de Juiz de Fora - Campus Avançado de Governador Valadares (UFJF-GV).

${ }^{2}$ Universidade Federal de Viçosa - UFV
} 


\section{INTRODUÇÃO}

A administração pública tem passado por intensas mudanças, principalmente depois da década de 1970 com a crise mundial do petróleo, em que o papel do Estado foi fortemente questionado. A partir disso, os parâmetros da administração pública deixam de seguir um paradigma burocrático e buscam a implementação de nova forma de gestão, comprometida com a otimização dos recursos e melhores resultados para a sociedade.

Nesse contexto, elementos como transparência, accountability e participação social passam a ganhar destaque na gestão pública. Filgueiras (2011) destaca que com o processo de redemocratização na América Latina observa-se uma pressão da sociedade pelo aprofundamento da accountability e, consequentemente, aumento da transparência pública.

No Brasil, esses elementos passam a ter maior relevância com o advento da Constituição Federal (CF) de 1988, também conhecida como "Constituição Cidadã", que determina a publicidade como um dos princípios da administração pública e institui a obrigatoriedade dos órgãos administrativos em prestar contas do uso de recursos públicos, um dos parâmetros da accountability. Além disso, estabelece mecanismos de democracia direta e participativa com a criação de conselhos gestores de políticas públicas, nos níveis municipal, estadual e federal, com representação partidária do Estado e da sociedade civil.

De acordo com Rocha (2012), a democracia contemporânea busca estabelecer uma nova forma de interação entre o Estado e a sociedade, com base em uma esfera pública que não se reduz ao estatal. Nesse contexto, não há que se falar em uma totalidade social centrada no Estado. A esfera pública compreende não só as arenas políticas, mas também redes periféricas informais que constituem a base do agir comunicativo.

A transparência é resultante de um processo de atribuição de um novo sentido ao consagrado princípio constitucional da publicidade na administração pública, em que o acesso à informação torna-se não apenas um direito do cidadão, mas um dever do Estado.

Assim, para que a sociedade possa efetivamente entender e ser inserida nos processos de gestão pública é necessário que o governo seja transparente e fomente a participação da sociedade, por meio de uma atuação proativa, espontânea, pautada na ética, em que o próprio serviço público seja visto como extensão da cidadania, motivado por um desejo de servir os outros e de lograr objetivos públicos (DENHARDT, 2011).

No Brasil, segundo Rocha (2012) antes mesmo da Lei 12.527/2011 que trata do Acesso à Informação, os temas da transparência, da efetividade dos canais de participação, dos mecanismos para o exercício do controle social e dos limites referentes à divulgação de informações já se faziam presentes na agenda pública, seja pela mobilização das organizações da sociedade civil e da mídia, seja pela reivindicação, perante o Judiciário, da proteção de outros direitos por parte daqueles que se sentiram prejudicados pela divulgação de informações.

Com o advento do uso da internet o debate se intensifica, pois as tecnologias da informação são encaradas como novas formas de promover a transparência e fortalecer as relações entre o governo e os cidadãos.

Os debates sobre transparência tem ganhado notoriedade no meio acadêmico por revelar as necessidades de se ampliar as formas de responsabilização do governante e defender as formas de controle social. No entanto, o que se observa na literatura sobre transparência é que apesar dos autores reconhecerem a transparência além da simples publicização de informações, a maioria das contribuições 
teóricas se restringe à transparência como "disponibilização de informações de interesse público", ficando os demais atributos somente no campo teórico.

Diante do exposto, este artigo tem por objetivo identificar e aprofundar as análises sobre transparência com base nas correntes teóricas de administração pública propostas por Andion (2012). Trata-se de evidenciar as mudanças ocorridas na administração pública e salientar a continuidade de abordagens teóricas sobre transparência pública.

No estudo realizado por Andion (2012) são apresentadas quatro correntes teóricas predominantes no campo de Administração Pública no Brasil: (i) Estadocêntrica; (ii) Pluralista; (iii) Nova Administração Pública; e (iv) Novo Serviço Público. A autora apresenta as principais características de cada corrente e se apoia no modelo desenvolvido por Burrell e Morgan (2008) para identificar a qual paradigma cada corrente teórica estaria ancorada.

A hipótese central deste estudo é a de que apesar de se observar mudanças nos paradigmas de administração públicas há uma continuidade teórica nas abordagens sobre transparência, predominando uma concepção funcionalista do termo. Isso porque apesar das mudanças observadas, o que implicaria em revisão do conceito de transparência, ainda é predominante às abordagens de transparência com base na publicização e na eficiência o que remete a uma concepção funcionalista.

A contribuição do estudo está no fato deste se inserir no quadro de trabalhos que buscam aprofundar os debates teóricos de administração, em particular nas discussões com relação à transparência pública, uma vez que há predominância de trabalhos teóricos-empíricos sobre essa temática que estão mais voltados para o entendimento da realidade e não buscam o aprofundamento teórico.

Além dessa introdução e da conclusão, o estudo conta com quatro seções. Inicialmente discutemse os aspectos da Corrente Estadocêntrica e as abordagens da transparência visualizadas nesta corrente. Em seguida, apresentam-se as abordagens da transparência na Corrente Pluralista e na Nova Administração Pública, bem como aquelas abordagens da transparência relativas ao Novo Serviço Público.

\section{PROCEDIMENTOS METODOLÓGICOS}

Trata-se de um estudo bibliográfico, descritivo com abordagem qualitativa que busca analisar identificar e aprofundar as análises sobre transparência com base nas correntes teóricas de administração pública propostas por Andion (2012).

Para análise dos trabalhos foram escolhidas as principais revistas que apresentam enfoque na área pública ou que publica importantes trabalhos sobre o tema. Além disso, foram selecionados os trabalhos do Encontro da Associação Nacional dos Programas de Pós-Graduação em Administração (ENANPAD), por ser considerado o principal evento da área, conforme apresentado no Quadro 1:

Quadro 1: Fonte dos Trabalhos Analisados

\begin{tabular}{|c|c|}
\hline Revista/Evento & Classificação Qualis-Capes* \\
\hline Revista de Administração Pública & A2 \\
\hline Revista Organizações e Sociedade & A2 \\
\hline Revista Administração Pública e Gestão Social & B2 \\
\hline Revista do Serviço Público & B2 \\
\hline EnAnpad & E1 \\
\hline
\end{tabular}

Fonte: Dados da Pesquisa

* Trata-se de qualificação científica da Revista/Evento atribuída pela Coordenação de Aperfeiçoamento de Pessoal de Nível Superior (CAPES) que para revistas variam de A1 a C, dividido em 7 níveis, sendo que foi considerada a classificação de 2014. Já os eventos possuem classificação E1 e E2 sendo sua última versão de 2009. 
Os estudos analisados consideram aqueles publicados no período de janeiro de 2000 ao primeiro semestre de 2014, totalizando 25 trabalhos. A análise foi embasada nos conceitos de transparência apresentado pelos autores, sendo estes associados ao estudo desenvolvido por Andion (2012).

\section{TRANSPARÊNCIA NA CORRENTE ESTADOCÊNTRICA DE ADMINISTRAÇÃO PÚBLICA}

$\mathrm{Na}$ corrente Estadocêntrica, que está ancorada no paradigma funcionalista, a administração pública é tratada em primeiro momento como ciência jurídica e posteriormente como ciência administrativa, tendo como aportes teóricos conceitos da administração de empresas. Essa corrente é apresentada por Andion (2012) como a mais influente no Brasil sendo predominante desde os primórdios da administração pública no país no século XIX até o final da década de 1970 (ANDION, 2012).

O foco principal dessa corrente teórica é a ampliação da competência e da racionalidade funcional na administração pública. Apesar de abarcar diferentes teorias, os elementos comuns do pensamento Estadocêntrico é a visão unitária do estado que detém de forma centralizada todo o processo de políticas públicas, do estado regulador e interventor, da organização burocrática hierarquizada com base no modelo ideal de Marx Weber, do distanciamento entre técnica e política com predomínio da racionalidade instrumental e da visão de que os administradores públicos devem implementar políticas públicas e garantir as práticas burocráticas e científicas na administração pública (ANDION, 2012).

Nessa corrente teórica a transparência quase não é abordada porque conforme destaca Paes (2011) até o fim do período ditatorial, valia a regra de que toda informação era imprescindível à segurança nacional e, portanto, estas não podem ser divulgadas ao público. Prevalecia o direito a privacidade em detrimento ao direito a informação.

Jardim (2008) ressalta que o modelo burocrático, predominante na Corrente Estadocêntrica vai de encontro à transparência administrativa necessária ao governo. Para o autor o conceito de segredo oficial é inventado e definido pela burocracia que defende veemente essa atitude.

Monteiro (2006) parece corroborar com o modelo burocrático ao afirmar que "o processo de escolhas públicas opaco pode levar a boas deliberações, enquanto, em troca, a abertura limita a margem de negociação com grupos de interesses preferenciais."

A transparência informacional do Estado é superada pela opacidade informacional da administração pública, fenômeno historicamente associado ao modelo burocrático de Estado sustentado no Brasil até o final da década de 1970. Dessa forma não se desenvolve a cultura da transparência entre os funcionários públicos brasileiros, o que se apresentará futuramente como um entrave à transparência (JARDIM, 1995; PAES, 2011).

Com a crise do Estado brasileiro durante a década de 1980 observa-se um momento de transição na administração pública com a emersão de novas abordagens teóricas no campo.

\section{ABORDAGENS DA TRANSPARÊNCIA NA CORRENTE PLURALISTA}

A Corrente Pluralista promove a aproximação entre administração pública e ciência política devido a abertura democrática, os avanços promovidos pela constituição de 1988 e a ampliação da mobilização social. Os novos estudos enfatizam a participação social na definição de agendas públicas e na expansão do controle social. Seus estudos de caráter mais críticos e humanistas se apoiam no paradigma do humanismo radical e os estudos que tem por base as influências marxistas e neomarxistas estão ancorados no paradigma do estruturalismo radical (ANDION, 2012). 
Essa corrente teve como principal contribuição destacar a importância da sociedade civil enquanto ator político, tornando a administração pública brasileira mais aberta à participação popular. No entanto, o pluralismo radical conduz ao comportamento anti-institucional o que enfraquece tanto o Estado quanto a democracia representativa (ANDION, 2012).

Neste sentido Gomes (2003) coloca que os conselhos gestores possuem potencial para se tornarem instância de controle social democrático, principalmente devido ao seu caráter plural e deliberativo, ao âmbito local e ao escopo setorial da política pública.

Apesar de haver maior interesse pela discussão da transparência após a abertura democrática não se observam, no campo de administração pública do Brasil, estudos que abordem a temática e enfatizem a transparência como indutora de mobilização da sociedade civil, enquanto sujeito de mudança social e nem que considerem o Estado como espaço de conflitos entre classes sociais. Portanto, não se encontram estudos que corroborem com os ideais da Corrente Pluralista.

\section{ABORDAGENS SOBRE TRANSPARÊNCIA NA NOVA ADMINISTRAÇÃO PÚBLICA}

Concomitante à abertura democrática e as primeiras experiência de gestão mais participativa nos anos de 1990, começam a chegar ao Brasil as propostas da Nova Administração Pública (NAP). Ancorada no paradigma funcionalista, a NAP apresenta-se como resposta a crise do Estado de Bem Estar Social. A partir de princípios mercadológicos a administração pública passa a ser vista como ciência do gerenciamento (ANDION, 2012).

Dentre as características desse novo modelo de administração encontra-se a cultura gerencial voltada para resultados, ênfase na regulação, interesse público correspondente à soma dos interesses privados, busca de regras racionais para entender o comportamento dos atores políticos, administradores públicos sendo vistos como empreendedores, controle fiscal, avaliação de desempenho, transparência na ação pública, importância das privatizações e o fortalecimento de arranjos institucionais competitivos e modernos (ANDION, 2012).

As abordagens da transparência que remetem a NAP são predominantes no meio acadêmico brasileiro. Nesses estudos são enfatizados princípios do modelo de gestão como regulação, eficiência, foco nos resultados, controle fiscal, análise de desempenho e a própria transparência.

Os estudos que se dedicam a regulação têm como base de análises as leis que regulamentam a transparência dos órgãos governamentais no Brasil, as quais destacamos a Lei de Responsabilidade Fiscal (Lei Complementar $n^{\circ}$ 101/2000), Lei da Transparência (Lei Complementar $n^{\circ}$ 131/2009) e mais recentemente a Lei de Acesso a Informação (Lei n 12.527/2011). Além de relatarem que as políticas em prol da transparência no país tem forte influência de organismos internacionais como a Organização das Nações Unidas (ONU), Organização para Cooperação para o Desenvolvimento Econômico (OCDE) e do Banco Mundial.

No âmbito de regulação, há de se destacar também os trabalhos de Campos, Ávila e Silva Jr. (2000) e Prado (2006) que revelam a importância da transparência nos órgãos estatais reguladores como, por exemplo, na ANEEL, e apontam que essa é resultado da participação do público interessado. Além disso, consideram que a transparência tem papel importante na legitimação das agências reguladoras perante a sociedade.

Nessa mesma vertente, Ferreira Junior (2003) destaca a importância dos contratos de gestão como mecanismo para melhorar a transparência, assim como pode ser observado no funcionamento dessas agências. 
As abordagens sobre controle fiscal, que também se baseiam em leis e regulamentação podem ser observadas nos estudos de Paes (2011), Rodrigues e Amorim Neto (2013), ou nos trabalhos que propõe a construção de índices de transparência como Paiva e Zuccolotto (2009), Cruz et al. (2012) e Ribeiro e Gomes (2012). Observa-se que nesse tipo de abordagem a transparência muitas vezes é restrita à disponibilização de informações financeiras, cuja proposta central é a análise da transparência fiscal como forma de controle fiscal do Estado.

Ressalta-se que conforme abordam autores como Sartori (2001) e Matias-Pereira (2010) a transparência ultrapassa a simples disponibilização de informações, uma vez que é necessário o atendimento de outros atributos como a qualidade, a compreensibilidade e a tempestividade. Em outras palavras, para ser útil à sociedade a informação deve ser verdadeira, objetiva e compreensível.

No âmbito da eficiência, há um grupo de autores que abordam a transparência como fator contribuinte para a eficiência e para a confiabilidade de órgãos públicos. Cezar, Barbosa e Reis (2013) consideram que a melhoria da comunicação governamental aumenta a transparência, sendo capaz de apresentar consequência direta na eficiência e confiabilidade. Costa, Macabeu e Ferreira (2012) acreditam que a transparência gera confiabilidade e eficiência. Antero (2006) pondera que a avaliação formal de políticas públicas gera transparência e consequentemente aumenta a eficiência na execução das políticas.

A abordagem desses autores segue o raciocínio de que a transparência seria responsável pela disponibilização de informações e que de posse dessas informações a sociedade pode cobrar maior eficiência dos órgãos responsáveis pela gestão de recursos que, consequentemente, aumentariam seus desempenhos. No entanto, os estudos se restringem a publicização de informações e não analisam a forma como a sociedade é inserida e atua nesse processo.

Autores como Prado (2006), Prado e Loureiro (2006) e Cezar, Barbosa e Reis (2013) apontam a transparência como requisito fundamental para a accountability e declaram que somente munida de informações a sociedade pode responsabilizar os governantes pelos seus atos. No entanto, não destacam o papel da sociedade frente à transparência, mas somente a disponibilização das informações de interesse público.

Nesta mesma linha de raciocínio Pimenta (1998), Ferreira Junior (2003), Peci, Pieranti e Rodrigues (2008), Ribeiro e Gomes (2009) e Oliveira Jr., Jordão e Costa Jr. (2014) apontam a transparência como elemento essencial para a atuação do controle social, destacando que esse só pode ser exercido se as informações forem disponibilizadas à sociedade. No entanto, não abordam o gap existente entre transparência e controle social deixando em aberto o caminho do acesso à informação a como exercer o controle sobre atos governamentais.

O aprofundamento do conceito de transparência pode ser visualizado nos estudos de Gelis Filho (2006) que aborda a necessidade de compreensão por parte dos stakeholders das informações disponibilizadas e de Araujo e Grossi (2013) que consideram a evolução no conceito de transparência devido às mudanças na administração pública. Entretanto, a análise empírica desses autores se baseia apenas na disponibilização de informações sem o avanço apresentado nas discussões teóricas.

Estudos realizados por Loureiro, Teixeira e Prado (2008) e Peci, Pierante e Rodrigues (2008) podem ser considerados de transição, pois já demonstram abordagem mais crítica sobre transparência e os princípios do gerencialismo. Loureiro, Teixeira e Prado (2008) enfocam a qualidade da informação, revelando se elas realmente são disponibilizadas de forma clara, objetiva e em tempo hábil para sua utilização.

Peci, Pierante e Rodrigues (2008) relatam que a busca pela eficiência se contrapõe aos regimes democráticos que devem ter por base a transparência. Nesse sentido, na nova administração pública é Preciso buscar mecanismos que atendam as necessidades de eficiência condicionada à transparência 
e vigência do regime democrático.

Apesar desses estudos de fronteira, são predominantes as abordagens de transparência que se restringem a disponibilização de informações e que estão relacionados à eficiência, confiança e controle fiscal, remetendo a concepção funcionalista do termo.

As principais críticas voltadas à NAP concentram-se em seu viés administrativo e economicista, pois não levam em consideração na reforma e resposta a crise do Estado às dimensões políticas e institucionais (ANDION, 2012).

Como pode se observar as abordagens da transparência dentro dessa corrente teórica também estão pautadas no viés administrativo, principalmente na eficiência e controle fiscal. A transparência é apresentada como a disponibilização de informações que é vista como obrigação do Estado. No entanto, questiona-se: Qual a validade da transparência se a sociedade não tiver a iniciativa de utilizar as informações? Tem-se que assim como na administração pública, as abordagens da transparência na corrente da NAP negligenciam a dimensão política e institucional.

Diante dessas limitações, são desenvolvidas mais recentemente novas correntes de pensamentos que tem como foco principal o revigoramento do Estado e dos gestores públicos de maneira que esses possam melhorar os serviços prestados aos cidadãos e a sociedade. Assim, a preocupação com o desempenho torna-se secundária, pois a primeiramente há a necessidade de desenvolver novos padrões de relacionamento entre Estado e sociedade abrangendo novamente as dimensões políticas de institucionais (ANDION, 2012).

\section{NOVO SERVIÇO PÚBLICO E AS ABORDAGENS SOBRE TRANSPARÊNCIA}

A corrente teórica do Novo Serviço Público (NSP) que se apoia no paradigma interpretativo, constitui um novo modelo de gestão que tem como referência as teorias democráticas e de cidadania. As concepções teóricas se baseiam nos modelos de comunidade e de sociedade civil que destacam a importância do poder local, humanismo organizacional e na teoria do discurso que enfatizam a importância do dialogo entre os diferentes agentes que atuam na esfera pública. Nesse novo contexto o cidadão torna-se protagonista na prestação do serviço público e na promoção da transformação social (ANDION, 2012).

As principais características do NSP são destacadas por Denhardt (2011) ao considerar que nesse modelo o interesse público é o alvo principal e não um subproduto, retomando o conceito de cidadão em detrimento de consumidor.

Os gestores públicos devem guiar e mediar ações coletivas e não simplesmente guiar a máquina pública. Deve-se pensar estrategicamente e agir democraticamente a fim de que políticas e programas públicos sejam construídos e implementados por meio de processos colaborativos e de coprodução (DENHARDT, 2011).

O território deve ser espaço privilegiado de intervenção pública enquanto lócus de identidade e recursos específicos. A accountability deve ser vista para além da prestação da prestação de contas e dever levar em consideração leis, normas, valores comunitários e interesses do cidadão. A cidadania deve ser colocada acima do empreendedorismo, desviando o foco da eficácia (DENHARDT, 2011).

No Brasil, a influência das ideias do NSP é observada timidamente após o processo de redemocratização, pois há ações como descentralização entre as esferas de governo, com destaque para a municipalização, criação de novos espaços públicos de participação da sociedade civil como os plebiscitos, conselhos e audiências públicas (ANDION, 2012). 
Surgem novos conceitos de destaque na administração pública como governança e território. Os conceitos de participação social e accountability, assim como o papel da sociedade civil e do cidadão são revistos e ampliados. As discussões são baseadas no fortalecimento da relação Estado-sociedade e são desenvolvidos espaços de diálogos entre cidadãos e governos. O cidadão passa a ser protagonista e principal responsável por sua condição social, compartilhando a responsabilidade de desenvolvimento em âmbito local com o estado.

As abordagens de transparência nessa corrente teórica são mais amplas e tem o enfoque servir de mecanismo facilitador da comunicação entre governo e sociedade, sendo que o papel da sociedade agora é amplamente discutido. A responsabilidade de ser transparente é cobrada tanto do governo, responsável por disponibilizar as informações, quanto da sociedade que tem o papel de exigir as informações que lhe competem.

Sousa et al. (2014) influenciada por Tenório (2011) considera que transparência não se restringe somente a permissão de acesso a certos dados de projetos, programa e políticas públicas, mas sim à possibilidade de todo cidadão obter e interpretar a informação completa, relevante, oportuna, pertinente e confiável sobre a gestão do projeto/programa e/ou políticas públicas.

Carneiro e Brasil (2007) relatam que na gestão participativa ao compartilhar os diferentes temas com a comunidade e buscar soluções que atendam ao coletivo contribui-se para o crescimento das partes, aumentando a transparência e a responsabilidade de todos no alcance dos objetivos escolhidos. Observa-se que a responsabilidade é compartilhada e não centrada somente no Estado como era percebido no modelo anterior.

Com uma abordagem sociocêntrica, Schommer, Dahme e Spaniol (2014) destacam o papel da transparência para o controle social e leva em consideração o papel de organismos institucionais ao pressionarem o Estado para criação de mecanismos de transparência.

Ruediger (2003) destaca o papel das tecnologias de informação na promoção da governança pública e relata que transparência e interação entre sociedade civil e sociedade política são os eixos centrais de possibilidades de reestruturação do Estado. No entanto, o autor adverte que ainda é necessário lutar contra as assimetrias históricas resultantes das estruturas burocráticas somadas a nova assimetria do acesso ao mundo digital.

A questão da transparência demanda não só um papel democrático do governo, mas também uma capacidade política da sociedade civil o que possibilita o diálogo entre os agentes que atuam na esfera pública (PINHO; IGLESIAS; SOUZA, 2005).

Para Sá (2006) os mecanismos que reforçam a transparência institucional e tem como base a gestão participativa, mais do que a força da cultura e do poder, conduzem ao sucesso de determinada formulação de estratégia possibilitando maior garantia de sustentabilidade às políticas.

Por essas abordagens pode-se observar que há mudança nos estudos sobre transparência com foco maior no fortalecimento da relação entre Estado e sociedade e no protagonismo do cidadão evidenciando uma concepção mais interpretativa do termo. Nas propostas no NSP a transparência torna-se elemento fundamental para que todos os agentes possuam as mesmas informações de maneira a fortalecer o processo de participação e a gestão de territórios.

No entanto, conforme observa Andion (2012) ainda não são observadas mudanças significativas no padrão de relações entre Estado e sociedade, sendo que ainda permanece alto nível de centralização e isolamento burocrático dos gestores públicos. Além disso, há forte influência da Corrente Patrimonialista principalmente no que concerne a gestão pública municipal. 


\section{CONSIDERAÇÕES FINAIS}

A análise das abordagens sobre transparência no Brasil com base nas correntes teóricas propostas por Andion (2012) permite concluir que predominam os estudos com base nos princípios da Nova Administração Pública. Os trabalhos dos autores que seguem essa corrente enfatizam a concepção gerencialista e funcionalista dos sistemas sociais, no intuito de desenvolver um estado voltado para resultados e com foco nos clientes (cidadãos). Dessa forma são recorrentes estudos com foco na disponibilização das informações públicas, no controle fiscal, na eficiência e na confiança do cidadão em relação ao estado.

A transparência é abordada como função exclusiva do Estado, que deve fornecer as informações de forma que suas ações possam ser controladas, com base em uma concepção funcional em que é dada ênfase na concepção de leis universais que permitam explicar os fatores que influenciam a transparência das informações públicas. Destaca-se que as informações dizem respeito apenas a finanças e orçamentos, com foco no resultados de políticas públicas. Quase não se observam estudos que abordam a transparência de decisões governamentais e de implementação das políticas públicas.

Essas evidências vão ao encontro com as considerações apontadas por Andion (2012) de que "o predomínio do paradigma funcionalista na administração pública brasileira tem estimulado uma visão objetivista no campo, com pouco espaço para a historicidade, o conflito e a subjetividade dos atores políticos". O mesmo acontece à abordagem predominante sobre transparência que busca encontrar uma solução objetiva para as políticas de transparência do estado e não levam em consideração a dimensão política e subjetiva dos atores envolvidos, uma vez que a transparência é revestida somente como função do Estado.

As novas abordagens, que remetem a corrente teórica do Novo Serviço Público e a uma concepção interpretativa, desenvolvem novas bases de compreensão da transparência que englobam aspectos subjetivistas e políticos. Além disso, abrange todo processo governamental desde a formulação até os resultados de políticas públicas constituindo espaços para cooperação e coprodução e destacando o papel fundamental da comunidade local, do cidadão ou na sociedade civil.

Dessa forma, a transparência não se remete somente a resultados de políticas públicas, mas também as decisões governamentais que agora tendem a ser tomadas em conjunto e ao processo de execução das políticas.

Apesar dos avanços ainda é preciso encarar dois desafios principais. O primeiro é a consolidação das abordagens de transparência com base na corrente teórica do NSP, pois ainda são poucos e tímidos com relação às abordagens da corrente teórica predominante. O segundo está relacionado com o engajamento da sociedade civil enquanto ator ativo nos espaços públicos. Os estudos demonstram avanços na melhoria da transparência, no entanto, ela perde o sentido se as informações não forem utilizadas para promover a accountability e o controle social. Assim, são necessárias ações que busquem a inserção da sociedade civil no processo governamental e a mudança na cultura de tutelado do estado para protagonista da transformação social.

\section{REFERÊNCIAS}

ANDION, C.. Por uma nova interpretação das mudanças de paradigma na administração pública.

Cadernos EBAPE.BR: Rio de Janeiro, v10, n1, p.1-19, 2012. 
ANTERO, S.A. Monitoramento e avaliação do Programa de Erradicação do Trabalho Escravo. Revista de Administração Pública: Rio de Janeiro, v42, n5, p.791-828, 2008.

ARAUJO, W.P.de; GROSSI, M.E.Del. Avaliação da transparência das informações sobre políticas de apoio aos produtores rurais no Brasil. Revista do Serviço Público: Brasília, v64, n4, p.447-464, 2013.

BURREL, G; MORGAN, G. Sociological Paradigms and Organisational Analysis. Hants: Ashgate, 2008.

CAMPOS, A.M.; AVILA, J.P.C.; SILVA JR, D.S. da. Avaliação de agências reguladoras: uma agenda de desafios para a sociedade brasileira. Revista de Administração Pública: Rio de Janeiro, v34, n5, p.2946, 2000.

CARNEIRO, R.; BRASIL, F. P. D. Descentralização e gestão local: uma análise de desenho e implementação do programa SOMMA em municípios mineiros. In: Encontro Nacional da Associação Nacional dos Programas de Pós-Graduação em Administração, Anais... Rio de Janeiro, 2007.

COSTA, C.C.de M.; MACABEU, A. A. V.; FERREIRA, M.A. M.. Análise da relação principal-agente nos regimes próprios de Previdência Social: o caso do Agros. Revista do Serviço Público Brasília, v63, n4, p.519-539, 2012.

CRUZ, C.F.et al.Transparência da gestão pública municipal: um estudo a partir dos portais eletrônicos dos maiores municípios brasileiros. Revista de Administração Pública: Rio de Janeiro, v46, n1, p.153-176, 2012.

DENHARDT, R.B. Teorias da Administração Pública. São Paulo: Cengage Learning, 2011.

FERREIRA JUNIOR, W.C.. Gerenciamento de hospitais estaduais paulistas por meio das organizações sociais de saúde. Revista de Administração Pública: Rio de Janeiro, v37, n2, p.243-264, 2003.

FILGUEIRAS, F.. Além da Transparência: Accountability e Política da Publicidade. Lua Nova, São Paulo, n. 84, pp. 353-364, 2011.

GELIS FILHO, A.. Análise comparativa do desenho normativo de instituições reguladoras do presente e do passado. Revista de Administração Pública: Rio de Janeiro, v40, n4, p.589-613, 2006.

GOMES, E.G. M.. Conselhos gestores de políticas públicas: democracia, controle social e instituições. 2003. 112f. Dissertação (Mestrado em Administração Pública). Escola de Administração de Empresas de São Paulo, Fundação Getúlio Vargas, São Paulo, 2003.

JARDIM, J.M.. A face oculta do Leviatã: gestão da informação e transparência administrativa. Revista do Serviço Público: Brasília, v59, n1, p.81-92, 2008.

LOUREIRO, M.R.; TEIXEIRA, M.A.C.. PRADO, Otávio. Construção de Instituições Democráticas no Brasil Contemporâneo: Transparência das Contas Públicas. Organizações e Sociedade: Salvador, v15, n47, 2008.

MATIAS-PEREIRA, J.. A Governança Corporativa aplicada no setor público brasileiro. Administração Pública e Gestão Social, v. 2, n. 1, p. 109-134, 2010.

MONTEIRO, J.V.. Intermediação política, transparência decisória e atendimentos preferenciais. Revista de Administração Pública: Rio de Janeiro, v40, n4, p.741-750, 2006.

OLIVEIRA JÚNIOR, T.M.de; JORDÃO, C.da S.; CASTRO JUNIOR, J.de L. P.. Transparência, monitoramento e avaliação de programas no Brasil: em busca de opacidades que podem restringir o exercício do controle social. Revista do Serviço Público Brasília, v65, n1, p.25-47, 2014. 
PAES, E. B.. A construção da Lei de Acesso à Informação Pública no Brasil: desafios na implementação de seus princípios. Revista do Serviço Público. Brasília, n62, v4, p.407-423, 2011.

PAIVA, C. P.de; ZUCCOLOTTO, R.. Índice de transparência fiscal das contas públicas dos municípios obtidos em meios eletrônicos de acesso público. In: Encontro Nacional da Associação Nacional de PósGraduação em Administração, Anais..., São Paulo, 2009.

PECI, A.; PIERANTI, O. P.; RODRIGUES, S.. Governança e New Public Management: Convergências e Contradições no Contexto Brasileiro. Organizações e Sociedade, v15, n46, p.39-45, 2008.

PIMENTA, C.C.. A reforma gerencial do Estado brasileiro no contexto das grandes tendências mundiais. Revista de Administração Pública: Rio de Janeiro, v32, n5, p.173-199, 1998.

PINHO, J.A.G. de; IGLESIAS, D.; SOUZA, A.C.P. Governo eletrônico, transparência, accountability e participação: o que portais de governos estaduais no Brasil mostram. In: Encontro Nacional da Associação Nacional de Pós-Graduação e Pesquisa em Administração, Anais... 2005.

PRADO, O.. Agências reguladoras e transparência: a disponibilização de informações pela Aneel. Revista de Administração Pública: Rio de Janeiro, v40, n4, p.631-646, 2006.

O.; LOUREIRO, M.R.G.. Governo Eletrônico e Transparência: Avaliação da Publicização das Contas Públicas das Capitais Brasileiras. Alcance, v13, n3, p. 355 - 372, 2006.

RIBEIRO, C. P.de P.; GOMES, A.P.. Transparência Fiscal na Gestão Pública Municipal no Estado de Minas Gerais. Encontro Nacional da Associação de Pós-Graduação em Administração, Anais... Rio de Janeiro, 2009.

ROCHA, H. H.N.. Transparência e accountability no Estado Democrático de Direito: reflexões à luz da Lei de Acesso à Informação. Revista do Tribunal de Contas do Estado de Minas Gerais: Minas Gerais, edição especial, p. 84-95, 2012.

RODRIGUES, K. F.; AMORIM NETO, O.. Relações Civis-Militares e Leis de Acesso Livre à Informação na América Latina. In: Encontro Nacional da Associação de Pós-Graduação em Administração, Anais... Rio de Janeiro, 2013.

RUEDIGER, M.A.. Governança democrática na era da informação. Revista de Administração Pública: Rio de Janeiro, v37, n6, p.1257-1280, 2003.

SÁ, M.L.D.de. Mecanismos de sustentabilidade das políticas de vigilância sanitária: um olhar sobre a Anvisa. Revista do Serviço Público: Brasília, v57, n4, p.489-505, 2006.

SCHOMMER, P. C.; DAHMER, J.; SPANIOL, E. L.. Controle Social no Brasil - Estadocêntrico ou Sociocêntrico? Evidências da $1^{\text {a }}$ Conferência Nacional sobre Transparência e Controle Social, Consocial. Administração Pública e Gestão Social: Viçosa, v.6, n.1, p. 35-47, 2014.

SOUSA, Y. M.et al. Gestão Social e Governança Urbana: O Caso do Portal da Amazônia, Belém - PA. Administração Pública e Gestão Social, n6, v1, p.27-34, 2014.

TENÓRIO, F.G.. (Re)Visitando o Conceito de Gestão Social. Desenvolvimento em questão, v 3, n5, p. 101-124, 2011. 
